Even if there has been pyloric obstruction before operation the return of gastric function is usually normal after vagotomy and drainage. Most of the delays in gastric emptying after vagotomy probably result from stromal dysfunction, for similar problems are sometimes seen after gastric resection without vagotomy. 9

The late complications following the various vagotomy operations result from (1) drainage operation, (2) denervation of other viscera, and (3) incomplete nerve section, which results in recurrent ulceration.

Any procedure for gastric drainage destroys or bypasses the normal mechanism controlling gastric emptying, and the "osmotic shield" function of the stomach is lost. The rapid transfer of hyperosmolar solutions into the small bowel results in dumping. Avoidance of the drainage procedure in the operation of highly selective vagotomy leads to a very low incidence of dumping. ${ }^{10}$

Denervation of the gall bladder causes demonstrable radiological change in gall bladder function, ${ }^{11}$ but as yet there is no clear evidence that this leads to an increase in formation of gall stones.

Post-vagotomy diarrhoea probably results from a combination of unregulated gastric emptying and denervation of the small bowel. It occurs in about $25 \%$ of patients after truncal vagotomy. For the majority the increased frequency of bowel action is an unexpected bonus of the operation. The incidence of severe and disabling diarrhoea is low, probably about $1 \%$. In a recent study the effect of ingesting $350 \mathrm{ml}$ of $25 \%$ glucose on an empty stomach was compared in three groups of patients. ${ }^{12}$ It resulted in diarrhoea in $67 \%$ of patients after truncal vagotomy with pyloroplasty, in $60 \%$ patients after truncal vagotomy with pyloroplasty, in $60 \%$ only $13 \%$ after highly selective vagotomy with no drainage procedure. These results suggest that uncontrolled gastric emptying may play a major part in the development of diarrhoea.

The long-term nutritional and metabolic disturbances after vagotomy and gastroenterostomy ${ }^{13}$ probably result from a combination of reduced acid secretion and uncontrolled gastric emptying.

Although incomplete nerve section is not a complication of the operation, it is a calamity for the patient who develops recurrent symptoms. Surgeons vary greatly in their ability to denervate the stomach, and success is not always related to experience. ${ }^{14}$ Incomplete nerve section would be avoided if a simple method existed for the recognition of a complete vagotomy. Though good results have been reported with the electrical stimulation test, ${ }^{15}$ this method has not been widely adopted.

Highly selective (proximal gastric vagotomy) seeks to avoid most of the late complications attributable to vagotomy. It is the logical development of vagal section, for it denervates only the secretory cell mass, leaving the gastric antrum, pylorus, and duodenum intact. It obviates the need for a drainage procedure. The early results are encouraging in the main, but really long-term follow-up results are required before a full and objective assessment can be made of its place in the surgery of duodenal ulcer.

Wirthlin, L. S., and Malt, R. A., Surgery, Gynecology and Obstetrics, 1972, $135,913$.

2 Price, J. J., Powis, J. A., and Morrissey, D. M., British fournal of Surgery, $1972,59,936$

Rosenberg, M., Lancet, 1968, 2, 379.

- Musgrove, J. E., Annals of Surgery, 1972, 175, 67

Guillory, J. R., and Clagett, O. T., Surgical Clinics of North America, $1967,47,833$.

- Edwards, D. A. W., Lancet, 1970, 2, 90.
' Ruckley, C. V., Falconer, C. W. A., Small, W. P., and Smith, A. N., British fournal of Surgery, 1970, 57, 245.

Buckler, K. G., Gut, 1967, 8, 137.

- Mathieson, A. J. M., British Yournal of Surgery, 1965, 52, 657.

${ }^{1}$ Humphrey, C. S., Johnston, D., Walker, B. E., Pulvertaft, C. N., and Goligher, J. C., British Medical fournal, 1972, 3, 785 .

11 Tinker, J., Lawson, T. R., and Cox, A. G., Gut, 1968, 9, 733 12 Johnston, D., Humphrey, C. S., Walker, B. E., Pulvertaft, C. N., and 18 Wheldon, E. J., Venables, C. W., and Johnston, I. D. A., Lancet, 1970, 1,

14 Johnston, D., and Goligher, J. C., Gut, 1971, 12, 963.

15 Burge, H., and Vane, J. R., British Medical fournal, 1958, 1, 615.

\section{A Marker for Medullary Carcinoma of Thyroid}

Medullary carcinoma of the thyroid is a tumour of the parafollicular or C cells, which normally produce calcitonin. ${ }^{1}$ Tumour cells continue to synthesize and secrete large amounts of calcitonin, and detection of increased amounts of this hormone in the circulation has provided a biochemical marker for the disease. A number of other humoral agents may be secreted by the medullary carcinoma, including 5-hydroxytryptamine, corticotrophin, ${ }^{2}$ prostaglandins, ${ }^{3}$ and histaminase. ${ }^{4-6}$

Histaminase is an enzyme that catalyses the deamination of histamine in tissues. High enzyme activity is found normally only in human intestine, kidney, and placenta, and levels of the enzyme in the serum increase during pregnancy and after injection of heparin. High tissue histaminase activity is found consistently in medullary carcinoma of the thyroid and its metastases, but not in other tumours, 56 and it appears to be a specific marker for medullary carcinoma of the thyroid. In 59 patients with a variety of other diseases and neoplasms a raised serum concentration of histaminase was found only once-in a woman with metastatic adenocarcinoma of the breast. ${ }^{5}$ But serum histaminase levels are not always raised in patients with medullary carcinoma of the thyroid. Raised values were found in 21 out of 42 affected patients, including 14 from families with inherited medullary carcinoma and seven with sporadic disease. ${ }^{5}$ Patients with metastatic disease tend to have higher values than those with localized disease; 18 out of 26 patients with metastatic disease had raised levels, whereas in only 3 out of 16 of those with localized disease were serum histaminase levels high.5 The highest serum histaminase levels are seen in patients with pulmonary metastases.

What then is the place of histaminase activity measurements in the diagnosis and management of patients with medullary carcinoma of the thyroid? The finding of high basal calcitonin levels and an exaggerated calcitonin response to calcium infusion remains the best method of separating patients with early medullary carcinoma of the thyroid from normal persons.7 Raised serum histaminase activity provides further support for the presence of a medullary carcinoma of the thyroid and is evidence of extrathyroidal disease. After removal of the primary tumour, high serum histaminase activity suggests that residual tumour is present, even if the basal calcitonin has returned to normal. Measurements of histaminase activity in tissues removed from patients suspected of medullary carcinoma of the thyroid can complement microscopical examination of these tissues. ${ }^{6}$

Measuring the serum histaminase activity in cases of suspected medullary carcinoma of the thyroid is a further 
example of the use of measurements in serum or urine of tumour-produced substances in the diagnosis of certain tumours.

1 Cunliffe, W. J., et al., Lancet, 1968, 2, 63.

Williams, E. D., fournal of Clinical Pathology, 1967, 20, 395.

Williams, E. D., Karim, S. M. M., and Sandler, M., Lancet, 1968, 1, 22. Baylin, S. B., Beaven, M. A., Engelman, K., Sjoerdsma, A., New England Fournal of Medicine, 1970, 283, 1239

Baylin, S. B., Beaven, M. A., Keiser, H. R., Tashjian, A. H., and Melvin, K. E. W., Lancet, 1972, 1, 455

- Baylin, S. B., Beaven, M. A., Buja, L. M., and Keiser, H. R., American fournal of Medicine, 1972, 53, 723.

${ }^{7}$ Melvin, K. E. W., Miller, H. J., and Tashjian, A. H., New England fournal of Medicine, 1971, 285, 1115 .

\section{Vitreous Surgery}

New surgical techniques, instruments, and vitreous substitutes have opened an exciting era in the field of surgery of the vitreous of the eye. Cases of retinal detachment, which have hitherto been thought inoperable by conventional means, are being treated successfully with increasing frequency. Because of the failure of chemical and drug therapy in the treatment of vitreous haemorrhage, ophthalmic surgeons are turning to mechanical means of removing opaque vitreous from the eye.

Miniature scissors have recently been devised which enable vitreous bands and membranes to be cut in order to release vitreous traction on the retina. The blades are $5 \mathrm{~mm}$ in length and the part that enters the eye has a diameter of $1.6 \mathrm{~mm} .^{1}$ An instrument with an inflatable balloon at its tip has been used in positioning detached retina and in breaking adhesions between the detached retinal flap of a giant tear and the underlying retina in order to make it mobile and more accessible to surgery. ${ }^{2}$

The most significant advance in vitreous surgery has been the introduction of the vitreous infusion suction cutter, which has made seemingly untreatable disease of the vitreous treatable. The instrument, which is the size of a fountain pen, consists of three parts: an electric micromoter that drives the cutting mechanism; a suction system; and an infusion system. It is introduced into the vitreous cavity and simultaneously diseased vitreous is mechanically destroyed, aspirated, and replaced by a balanced salt solution, and vitreous strands are also eliminated. The action of the instrument is observed through a fundus contact lens with the operating microscope. Long-standing vitreous haemorrhage, vitreous membranes, and retinitis proliferans in diabetic patients, and difficult cases of retinal detachment with vitreous traction and giant tears, have been successfully treated by this method. The technique is tedious and long, requiring excellent surgical skill and judgement. So far the best results have been achieved in cases of long-standing vitreous haemorrhage. ${ }^{3}$ These heroic procedures should be confined to desperate cases, as treatment in the early stage of their development is hazardous.

The injection of vitreous substitutes into the vitreous cavity has been a useful adjunct in certain types of operations for retinal detachment. The purpose of these injections is to replenish the volume of the vitreous cavity and to restore normal intraocular pressure in eyes which are hypotonic after the drainage of subretinal fluid. By eliminating undesired folds in the retina and pushing the retina and retinal tears towards their required contact with the in- flamed choroid they also act as retinal splints. In certain cases vitreous substitutes are used to break down vitreous bands and membranes which, by exerting excessive pull on the retina, have rendered conventional methods of retinal reapposition ineffective.

Several liquids and gases are being tried with varying degrees of success. They include saline, human donor vitreous hyaluronic acid, silicone oil, and air. Attempts at vitreous transplantation by means of eye-bank donor vitreous have not proved to be entirely satisfactory owing to its rapid depolymerization after removal from the donor eye, rendering it no more viscid than water. Hyaluronic acid has been recently used with a moderate degree of success. It is superior to saline because of its higher viscosity and is well tolerated by the eye. Liquid silicone is a non-absorbable vitreous substitute with a high viscosity. Its use is reserved for patients with only one potentially useful eye which has an otherwise hopeless prognosis and no chance of cure by conventional procedures for treating retinal detachment. The long-term visual results with silicone are disappointing owing to the many late complications encountered, which include damage to the retinal cells. It has been used only in 37 hopeless cases of retinal detachment in the last nine years at the Retinal Unit of the High Holborn Branch of Moorfield Eye Hospital. ${ }^{4}$

Air is a useful substitute for vitreous and is absorbed a few days after its injection into the eye. Because of its low specific gravity its location within the eye can be controlled by altering the position of the patient's head postoperatively. This is of particular value in the treatment of giant retinal tears. ${ }^{5}$ Its main disadvantage is that it makes postoperative fundoscopy difficult.

The perfect vitreous substitute should be a gel with the same physical and optical properties as vitreous. Unfortunately gels cannot be injected through needles without fracturing them, and much more research in this field is necessary.

1 Couvillion, G. C., Freeman, H. M., and Schepens, C. L., Archives of Ophthalmology, 1970, 83, 722 .

2 Freeman, H. M., Couvillion, G. C., and Schepens, C. L., Archives of Ophthalmology, 1970, 83, 715 .

3 Machemer, R., Buettner, H., Norton, E. W. D. and Parel, J. M., Transactions of the American Academy of Ophthalmology and Otolaryngology, 1971, 75, 813.

4 Kanski, J. J., and Daniel, R., British fournal of Ophthalmology (in press).

5 Norton, E. W. D., Aaberg, T., Fung, W., and Curtin, V. T., American fournal of Ophthalmology, 1969, 68, 1011.

\section{Pilot Error}

The development of aircraft has brought them to a point where they can be flown by more automatic control than many airports permit. A high proportion are capable of partial automatic landing down to a height of 30 metres and a visual range on the runway of $\mathbf{4 0 0}$ metres, yet few airports allow this degree of automation, though Heathrow does do so. That pilots are capable of error like the rest of us is unfortunately true, as shown by a number of recent inquiries. But aircraft accidents remain a relatively rare circumstance in mass transportation. Much the largest proportion occur in the immediate neighbourhood of airports and are related to take-off and landing. Consequently the task that pilots undertake and the strains imposed on them during this part of the aircraft's flight, while being of special con- 